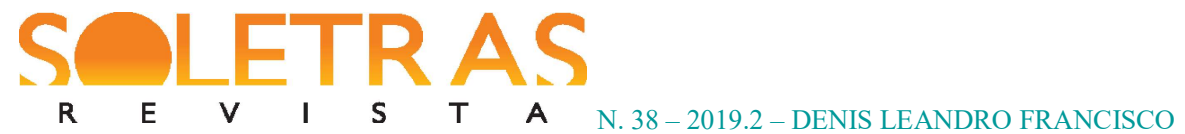

\title{
Uma dolorosa aprendizagem: espaço (d)e escrita em António Lobo Antunes ${ }^{1}$
}

\author{
Denis Leandro Francisco ${ }^{2}$
}

\begin{abstract}
Resumo: Este artigo relaciona espaço e escrita nos três livros de estreia do escritor português António Lobo Antunes: Memória de elefante (1979), Os cus de Judas (1979) e Conhecimento do inferno (1980). O objetivo é, partindo das noções de território, desterritorialização e reterritorialização (DELEUZE; GUATTARI, 1980; GUATTARI; ROLNIK, 1986), examinar o trânsito do então médicopsiquiatra Lobo Antunes pelo espaço africano durante a guerra colonial em Angola como aquilo que torna possível a escrita do texto literário ao ensejar, no escritor-em-formação, a conscientização do que Joseph Margolis (1975) definiu filosoficamente como negativities humanas - formas básicas de perda e limitação da vida e do sentido - e que Walter Benjamin $(1933,1936)$ relacionou à "destruição da experiência". A análise realizada indica que, simultaneamente à desterritorialização relativa do espaço angolano pela negatividade da guerra colonial processa-se a desterritorialização absoluta do médicopsiquiatra e sua reterritorialização em escritor.
\end{abstract}

Palavras-chave: António Lobo Antunes. Espaço. Negatividade. Re-desterritorialização. Escrita.

\section{Introdução}

- Tens escrito? interrogou.

De mês a mês desfechava de súbito esta pergunta aterradora, porque para o psiquiatra o manuseio das palavras constituía uma espécie de vergonha secreta, obsessão eternamente adiada. ANTUNES, Memória de elefante, p. 70.

Os livros de estreia de António Lobo Antunes - Memória de elefante (1979), Os cus de Judas (1979) e Conhecimento do inferno (1980) - estruturam-se sobre três grandes eixos ou topoi fundamentais: a guerra colonial portuguesa em Angola, a experiência psiquiátrica e a rememoração da infância. Dentre esses eixos, é de se notar, a partir tanto da leitura dos textos literários quanto da fortuna crítica do autor, que a temática da guerra colonial é a linha de força que mais se destaca nessas três obras que a crítica e o próprio autor têm considerado

\footnotetext{
1 Registro o meu agradecimento ao Prof. Sérgio Guimarães de Sousa, da Universidade do Minho, pela interlocução em Portugal e pela gentileza de presentear-me com um exemplar do Dicionário da obra de António Lobo Antunes.

${ }^{2}$ Doutor em literatura comparada (ênfase em literatura portuguesa). Atua como Assistant Professor na Hankuk University of Foreign Studies (HUFS), Seul/Coreia do Sul, onde atua na área de Português Língua Estrangeira e Literatura Brasileira. Coréia do sul. E-mail: denisleandro@outlook.com. (i) https://orcid.org/0000-0001-5947-8832
} 
como seus romances de formação, reunindo-os sob a denominação de "ciclo da aprendizagem" (ANTUNES apud ARNAUT, 2008, p. 214-215), designação sem dúvida pertinente, uma vez que essas três obras apresentam veios temáticos relativos à formação do escritor como tal, trazendo circunstâncias coincidentes entre as personagens ou os narradores antunianos e a pessoa civil António Lobo Antunes, como, por exemplo, o fato de o escritor ter servido na guerra colonial em Angola e, com formação em Medicina, ter trabalhado, até a publicação do seu primeiro livro, no hospital psiquiátrico Miguel Bombarda em Portugal.

As narrativas que compõem essa trilogia são apresentadas pela mesma voz que intercala as rememorações da infância e da guerra (plano temporal da representação da memória), mesclando-as à vida atual do médico psiquiatra (plano temporal da configuração diegética), em movimentos retrospectivos e prospectivos pouco demarcados, engendrando narrativas difusas e que encenam temporalidades fragilmente delineadas. Esse procedimento narrativo configura-se como a forma embrionária de toda a escrita antuniana: a das temporalidades, espacialidades e subjetividades múltiplas e desterritorializadas.

O próprio Lobo Antunes ocupa esse não-lugar da desterritorialização, da exterioridade e da desreferencialização: nascido em Lisboa, foi convocado pelo exército português para servir em Angola, entre 1970 e 1973, durante a fase final da guerra colonial portuguesa naquele país. O retorno definitivo desse sujeito escritor à "nação" portuguesa jamais se realizará por completo, tornou-se mítico, suspenso e sua ficção irá se fundar nessa fissura entre Angola e Portugal, nessa lacuna que operacionalizará a dinâmica de seus textos: nesse espaço exterior, nesse lugar sem lugar que seus textos asseguram - lugar este que é o de toda fala e de toda escrita quando estas não se deixaram seduzir pelo poder e pela Lei que a identidade (BARTHES, 1988) parece querer impor -, o sentido está sempre em movimento, se faz nessa movência que não conhece repouso, assim como as identidades traçadas pela sua ficção se fazem sempre num movimento de contraponto à alteridade desestabilizante do outro, num arranjo sempre instável e provisório (des)articulado por uma memória que busca incessantemente reterritorializar o espaço liso da guerra.

\section{Território, Desterritorialização e Reterritorialização}

Para o pensamento de Deleuze e Guattari, território é uma noção fundamental, assim definida: 
A noção de território é entendida aqui num sentido muito amplo, que ultrapassa o uso que dela fazem a etologia e a etnologia. Os seres existentes se organizam segundo territórios que os delimitam e os articulam aos outros existentes e aos fluxos cósmicos. O território pode ser relativo tanto a um espaço vivido, quanto a um sistema percebido no seio do qual um sujeito se sente "em casa". O território é sinônimo de apropriação, de subjetivação fechada sobre si mesma. Ele é o conjunto de projetos e representações nos quais vai desembocar, pragmaticamente, toda uma série de comportamentos, de investimentos, nos tempos e nos espaços sociais, culturais, estéticos, cognitivos (GUATTARI; ROLNIK, 1996, p. 323).

Um território é, portanto, formado por meio de vários agenciamentos ${ }^{3}$ e, como tudo pode ser agenciado (não apenas os espaços geográficos), a noção deleuze-guattariana de território engloba multiplicidades e não apenas a dimensão físico-geográfica. Ainda que, conforme Deleuze e Guattari, todo agenciamento seja, em primeiro lugar, territorial (1997, p. 218), há sempre uma outra dimensão - uma "territorialidade" - envolvendo um território, uma vez que essa noção assume, em sua amplitude, uma relação com o pensamento e com o desejo, isto é, com a intensidade criadora e produtiva:

[...] a primeira regra concreta dos agenciamentos é descobrir a territorialidade que envolvem, pois sempre há alguma: dentro da sua lata de lixo ou sobre o banco, os personagens de Beckett criam para si um território. Descobrir os agenciamentos territoriais de alguém, homem ou animal: "minha casa" [...] (DELEUZE; GUATTARI, 1997b, p. 218).

A partir de diferentes agenciamentos, tudo pode ser desterritorializado e reterritorializado, isto é, pode-se proceder a um movimento em direção ao abandono de um território (desterritorialização) e pode-se, da mesma forma, realizar diferentes agenciamentos para proceder à construção de um território (reterritorialização).

À discussão sobre a des-reterritorialização liga-se uma outra acerca do espaço liso e do espaço estriado. O espaço liso é aquele que "se constitui por acumulação de vizinhanças, e [no

\footnotetext{
${ }^{3}$ Por agenciamento, Deleuze e Guattari entendem "uma noção mais ampla do que a de estrutura, sistema, forma, etc. Um agenciamento comporta componentes heterogêneos, tanto de ordem biológica, quanto social, maquínica, gnosiológica, imaginária.” (1996, p. 317).
} 
qual] cada acumulação define uma zona de indiscernibilidade própria ao 'devir'” (DELEUZE; GUATTARI, 1997a, p. 197). Esse espaço, portanto, "dispõe sempre de uma potência de desterritorialização superior ao estriado" (DELEUZE; GUATTARI, 1997a, p. 187). Os espaços mobilizados nas três narrativas iniciais antunianas são, assim, predominantemente lisos, de simultânea amnésia e repetição maníaca, são também espaços desterritorializados, ou seja, espaços para os quais não há uma função a priori e que não agenciam qualquer identidade, estabilidade ou referência, mas cuja utilização/ocupação se faz a partir das descontínuas intensidades que ali serão produzidas a partir da rememoração engendrada pelo escritor-narrador.

O liso, Deleuze e Guattari fazem questão de frisar, não se confunde com o homogêneo, portanto, não se confunde com a identidade binária: ele é, ao contrário, o espaço onde a heterogeneidade pode se realizar sem ser coagida pelos vetores da homogeneidade. É precisamente o espaço liso e sem coordenadas da guerra, da infância e do hospital psiquiátrico que os narradores das obras iniciais antunianas irão, a partir de novos agenciamentos possibilitados pela escrita, reterritorializar à medida que narram suas histórias/escreverem seus romances.

Essa equação de desterritorialização-escrita-reterritorialização, contudo, não é tão simples. O liso e o estriado engendram complicações e superposições muito mais complexas que qualquer dicotomia pode prever, já que esses espaços "colocam em jogo movimentos dissimétricos” (DELEUZE; GUATTARI, 1997a, p. 189) nos quais as contaminações várias não permitem classificações estanques e compartimentadas dos espaços em "necessariamente lisos" ou "necessariamente estriados". Há que se perceber as distintas forças que atuam nesses espaços, que ora são forças intensivas de desterritorialização (a proximidade da morte no campo de batalha, a destruição dos mitos da infância, o cotidiano profissional desumanizador do médico-psiquiatra), ora são forças extensivas de reterritorialização (como o apego do narrador à terra angolana, à casa da infância e a certos funcionários do hospital onde trabalha). Nesse movimento, impulsionado pelas forças extensivas de desterritorialização, o narradorescritor-em-formação irá, em seu trabalho de escrita do(s) romance(s), mapear, estriar e, finalmente, reterritorializar esses "espaços-tempo" em um "espaço-tempo-de-escrita".

Nesse ponto, pode-se perceber que é impossível existirem territórios completamente estáveis, uma vez que todo território, necessariamente, comporta um vetor de desterritorialização e um outro vetor, de reterritorialização. Esses dois processos são, portanto, 
indissociáveis. Entretanto, a reterritorialização não se confunde com o retorno a uma forma anterior de agenciamento conformador de uma territorialidade precedente. Reterritorializar implica novos agenciamentos a partir de elementos desterritorializados:

[...] De forma que não se deve confundir a reterritorialização com o retorno a uma territorialidade primitiva ou mais antiga: ela implica necessariamente um conjunto de artifícios pelos quais um elemento, ele mesmo desterritorializado, serve de territorialidade nova ao outro que também perdeu a sua. Daí todo um sistema de reterritorializações horizontais e complementares [...] (GUATTARI; ROLNIK, 1996, p. 41).

Os processos de des-reterritorialização comportam intensidades que perfazem dois tipos de desterritorialização: a desterritorialização relativa e a desterritorialização absoluta. A primeira diz respeito aos agenciamentos socioculturais e a segunda remete ao próprio pensamento/à criação. Ambas estão imbrincadas e, para cada tipo de desterritorialização, conforme dissemos, pressupõe-se um movimento de reterritorialização.

Em suas considerações acerca da desterritorialização relativa ou desterritorialização do socius (DELEUZE; GUATTARI, s/d), Deleuze e Guattari desenvolvem uma historiografia da desterritorialização desde as sociedades tradicionais agrárias até as sociedades capitalistas industriais ou pós-industriais. De acordo com eles, por meio da desterritorialização das sociedades pré-capitalistas, fortemente territoriais porque ligadas à terra, o Estado e o sistema capitalista irão se constituir, procedendo à reterritorialização dessas sociedades e da sua "unidade primitiva, selvagem, do desejo e da produção" (DELEUZE; GUATTARI, s/d, p. 144): a terra. Sobre as formas originárias de agenciamentos e a territorialidade dessas comunidades pré-capitalistas, o Estado capitalista moderno irá sobrecodificar ${ }^{4}$ os seus agenciamentos e a sua territorialidade por meio do seu aparelho de poder despótico. Nos três romances iniciais de Lobo Antunes, a territorialidade do Estado português se fundará nesse processo de desterritorialização do território angolano (e de outros territórios africanos) e na sobrecodificação de sua territorialidade pela territorialidade imperial da metrópole. É esse processo que Lobo Antunes involuntariamente integra ao ser recrutado para servir na guerra

\footnotetext{
${ }^{4}$ A noção de codificação "é empregada numa acepção bem lata: ela pode dizer respeito tanto aos sistemas semióticos quanto aos fluxos sociais e aos fluxos materiais. O termo 'sobrecodificação' corresponde a uma codificação em segundo grau.” (GUATTARI; ROLNIK, 1996, p. 317-318).
} 
colonial em Angola e é a partir dessa dupla desterritorialização - da territorialidade angolana e da sua territorialidade médico-portuguesa - que Lobo Antunes irá se reterritorializar, dando início à sua "dolorosa aprendizagem" da escrita:

O espaço africano é um dos mais frequentemente presentes na obra de Lobo Antunes e, com a zona de Benfica, talvez o mais determinante. [...]. Na rotina de um país que a ignora ou esquece, África torna-se assombração fantasmática para quem, regressado, se vê compelido a viver como se nunca lá tivesse ido. A raiva dessa forçada irrealização solta-se sobretudo na longa elucubração do protagonista de CJ [Os cus de Judas], paradigmática da força obsessiva dessa ausência. (ABREU, 2008, p. 187-188, grifos nossos).

Para Deleuze a Guattari, pensar é desterritorializar: o pensamento, para se realizar, exige a desterritorialização, ou seja, o rompimento com um território já existente por meio da desconstrução de agenciamentos constitutivos do território anterior. Nesse processo, novos agenciamentos precisam ser formados, novas relações, novas funcionalidades, novas arquiteturas. Essa desterritorialização do pensamento irá abrir espaço para a criação de algo novo e, como a toda desterritorialização corresponde uma reterritorialização, a reterritorialização absoluta é, justamente, a obra de arte que se produz, o conceito que se elabora, a pintura que se finaliza, o texto que se escreve.

\section{Espaço (d)e escrita}

Isto é uma terra de excessos de toda ordem. Nada tem medida nem contenção: um pouco como a minha louca prosa, em que se cosem feridas com tiras de solda. ANTUNES, D'este viver aqui neste papel descripto: cartas da guerra, p. 302.

A força a um só tempo propulsora e desarticuladora da guerra colonial ficcionalmente recuperada nessas três narrativas antunianas de 1979-1980 irá impulsionar a escrita do texto pelo escritor-em-formação. Essa linha de força irá, de certo modo, catalisar os demais veios temáticos de que o texto antuniano se constitui, colocando em diálogo e tensionando todas as 
três narrativas. Não há como escapar à leitura dessa força de negatividade, assim como não houve para o escritor-narrador escapatória possível, posto que a guerra está, rigorosamente, em quase todos os espaços ocupados ou em vias de se ocupar:

O quimbo da Tia Teresa, cercado pelo odor doce dos pés de liamba e de tabaco, é talvez o único sítio em que a guerra não logrou invadir do seu cheiro pestilento e cruel. Alastrou por Angola [...], alcançou Portugal [...], insinuou-se na minha humilde cidade [...], encontrei-a deitada no berço da minha filha como um gato, fitando-me com pupilas de maldade oblíqua [...]. A guerra propagou-se aos sorrisos das mulheres dos bares [...]. Está aqui, nesta casa vazia, nos roupeiros desta casa vazia, grávida dos fetos moles das minhas cuecas, no geométrico espaço de trevas que as lâmpadas não alcançam nunca, está aqui e chama-me baixinho [...]. Está em si, no seu perfil sarcástico desprovido de amor [...]. Deito um centímetro mentolado de guerra na escova de dentes matinal [...]. De modo que, se faz favor, [...] expulse para o corredor o cheiro pestilento, e odioso, e cruel da guerra, e invente uma diáfana paz de infância para os nossos corpos devastados. (ANTUNES, 2003, p. 211, 212-214).

De tal forma plural e dispersivo se faz o poder devastador da guerra que ele não reconhece limites de espacialização, deslocando-se, atormentadoramente, de Angola a Portugal, por todo o texto. Para Joseph Margolis (1975, p. 4), a guerra constitui-se, filosoficamente, como uma das negativities humanas: formas básicas de perda e limitação da vida e do sentido. Para esse professor de filosofia e estética da Temple University, a guerra é de difícil definição filosófica e, enquanto negativity, não se restringe aos confrontos bélicos, de motivações geralmente econômicas ou territoriais, entre países ou estados-nação, como no caso da guerra colonial angolana, mas comporta também guerras metafóricas, como aquelas travadas contra a pobreza, a fome, a doença e a morte (MARGOLIS, 1975, p. 50).

Nesse sentido é que o espaço da guerra que essas ficções antunianas discursivamente mobilizam é aqui ampliado, assumindo uma extensão mais abrangente, avançando além do exclusivamente territorial e abarcando as multiplicidades da territorialidade, agenciando outras guerras metafórico-existenciais que se multiplicam e se entrecruzam, muitas vezes de forma latente, nesses três romances, proliferando-se em outras instâncias da existência: 


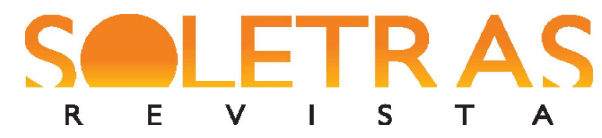

N. 38 - 2019.2 - DENIS LEANDRO FRANCISCO

Angola, pensou ele no restaurante da serra, diante de uma cerveja morna que sabia a baba de caracol e a espuma de banho, talvez que a guerra continue, de uma outra forma, dentro de nós, talvez que eu prossiga unicamente ocupado com a enorme, desesperante, trágica tarefa de durar, de durar sem protestos, sem revolta, de durar a medo como os doentes da $5^{\text {a enfermaria do }}$ Hospital Miguel Bombarda, fitando os psiquiatras num estranho misto de esperança e de terror [...] (ANTUNES, 2006a, p. 77, grifo nosso).

Outras manifestações dessa negativity, outras conformações de guerra operam, em negativo, nesse médico-psiquiatra: a "Arte da Catalogação da Angústia” (ANTUNES. 2006b, p. 10), a "dolorosa aprendizagem da agonia" (ANTUNES, 2003, p. 9) e o "conhecimento do inferno" (ANTUNES, 2006a, p. 22). Essas três frases-chave não apresentam significação unívoca e estanque nas narrativas, antes, são intercambiáveis e agenciam territorialidades variadas: tanto podem remeter às condições aterradoras da guerra e da psiquiatria para esse escritor-narrador angustiado, quanto às suas atribulações existenciais que comportam a solidão, o medo do fracasso, o esfacelamento das relações amorosas, o envelhecimento e a inescapável certeza da morte e do apagamento do ser. O espaço da guerra se ramifica, rizomaticamente (DELEUZE, GUATTARI, 1995b), em várias outras linhas de negatividade que se projetam tanto no âmbito do enunciado quanto no da enunciação. Em seu trânsito pelo espaço angolano, Lobo Antunes escreve e é escrito por outras menos tradicionais - mas nem por isso menos perturbadoras e arruinadoras - modalidades de guerra, as quais irão, simultaneamente, cingir seu universo ficcional e desencadear seu processo de escrita.

Esse topos da guerra movimenta, portanto, diferentes espacialidades e temporalidades ficcionais: espaços de exterioridade - Lisboa e Portugal, Angola e África, o Hospital Miguel Bombarda - e espaços de interioridade - a expatriação do escritor-narrador para servir em uma terra estranha e inóspita, o cotidiano e o ambiente hostis da psiquiatria, a falência do casamento e das relações amorosas. Esses espaços, certamente, comunicam-se, contaminamse e se perturbam mutuamente nas narrativas, formando a roda dentada que aciona e propulsiona todo o processo de escrita do texto literário. Essa desestabilização propulsora se dá também sob uma dimensão temporal: a temporalidade disfórica da guerra colonial perturba a temporalidade ficcional do presente da enunciação - e o sujeito nela imerso -, de tal forma que o plano da enunciação acaba por aderir ao plano do enunciado: 
Que sabe este tipo de África, interrogou-se o psiquiatra à medida que o outro, padeira de Aljubarrota do patriotismo à Legião, se afastava em gritinhos indignados prometendo reservar-lhe um candeeiro da avenida, que sabe este caramelo de cinquenta anos da guerra de África onde não morreu nem viu morrer, que sabe este cretino dos administradores de posto que enterravam cubos de gelo no ânus dos negros que lhes desagradavam, que sabe este parvo da angústia de escolher entre o exílio despaisado e a absurda estupidez dos tiros sem razão, que sabe este animal das bombas de napalm, das raparigas grávidas espancadas pela Pide, das minas a florirem sob as rodas das camionetas em cogumelos de fogo, da saudade, do medo, da raiva, da solidão, do desespero? Como sempre que se recordava de Angola um roldão de lembranças em desordem subiu-lhe das tripas à cabeça na veemência das lágrimas contidas: o nascimento da filha mais velha silabado pelo rádio para o destacamento onde se achava, primeira maçãzinha de oiro do seu esperma, longas vigílias na enfermaria improvisada debruçado para a agonia dos feridos, sair exausto à porta deixando o furriel acabar de coser os tecidos e encontrar cá fora uma repentina amplidão de estrelas desconhecidas, com a sua voz a repetir-lhe dentro - Este não é o meu país, este não é o meu país, este não é o meu país [...] (ANTUNES, 2006b, p. 4243).

A guerra rememorada emerge sempre como a mais absoluta desordem, invadindo violentamente o presente da enunciação, a tal ponto que se torna difícil separar essas duas temporalidades. A negatividade da guerra impõe não apenas ao narrado, mas também à narração, a dispersão que a própria luta armada apresenta, com seus eventos sem explicações, suas motivações absurdas - "quem me decifra o absurdo disto" (ANTUNES, 2003, p. 48) - e suas atrocidades incompreensíveis: a forma impetuosa e ingente dessa negatividade amalgama-se ao seu conteúdo, assim como a estranheza desse lugar desconhecido e estrangeiro - "Este não é o meu país" - entrelaça-se à estranheza dessa temporalidade algo disfórica e ilocalizável - "um roldão de lembranças em desordem" -, que se prolonga pela narrativa de forma explícita, como na passagem acima, ou fantasmática, como se observa em quase todo o texto. A desterritorialização subjetivo-espacial não se processa apenas no deslocamento Lisboa-Angola, mas opera também no sentido inverso, Angola-Lisboa:

Ao voltar da guerra, o médico, habituado entretanto à mata, às fazendas de girassol e à noção de tempo paciente e eterna dos negros, em que os minutos, subitamente elásticos, podiam durar semanas inteiras de tranqüila expectativa, tivera de proceder a penoso esforço de acomodação interior a fim de se reacostumar aos prédios de azulejos que constituíam as suas cubatas natais. A palidez das caras compelia-o a diagnosticar uma anemia 


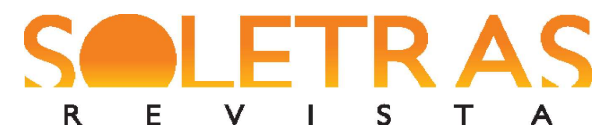

N. 38 - 2019.2 - DENIS LEANDRO FRANCISCO

colectiva, e o português sem sotaque surgia-lhe tão desprovido de encanto como um cotidiano de escriturário. [...]. Entre a Angola que perdera e a Lisboa que não reganhara o médico sentia-se duplamente órfão, e esta condição de despaisado continuara dolorosamente a prolongar-se porque muita coisa se alterara na sua ausência [...] (ANTUNES, 2006b, p. 102).

Esse escritor-narrador retornado de um país colonizado, ao ingressar novamente na “centralidade europeia", não se habitua a uma temporalidade tão distinta daquela vivenciada na "periférica África” senão por meio de um "penoso esforço de acomodação interior": o escritor-em-formação irá resgatar ficcionalmente essa inaptidão valendo-se de um discurso que, sempre algo "desconjuntado" ou disjuntivo em seus procedimentos de enunciação, homologa a inadequação temporal ao curso "truncado" das frases e dos períodos do seu texto literário. Esse escritor-narrador, ora desterritorializado pela guerra e reterritorializado pela terra angolana - "quem veio aqui não consegue voltar o mesmo, explicava eu ao capitão" (ANTUNES, 2003, p. 149) -, não reconhece seus conterrâneos - que crê serem todos portadores de uma estranha anemia coletiva - e aproxima o Português standard do colonizador à dimensão monótona do cotidiano de um escrevente burocrático, rebaixando a língua materna - em sua variante metropolitana - não à categoria de língua estrangeira, mas à de "uma língua qualquer", ressaltando a peculiar proximidade que esse escritor-narrador passa a estabelecer com a cultura e a territorialidade do colonizado.

Essa atração pela língua e pela cultura do colonizado, entretanto, irá mostrar-se ambivalente no decorrer da obra do escritor ${ }^{5}$, conforme observou Agripina Carriço Vieira:

Do conjunto da obra, emana uma imagística de Angola, construída a partir de uma dinâmica afectiva dual. [...].

\footnotetext{
5 Em D'este viver aqui neste papel descripto: cartas da guerra, tem-se uma generosa amostra da adesão conflituosa que o escritor-em-formação estabelece com a territorialidade angolana. Esse longo texto epistolar faz crer que a atração declarada desse escritor-narrador - "Este continente é maravilhoso de vida, de energia, de juventude, de imaginação. Para quem pertence a um país cansado faz bem ver estes verdes, estes sons, esta exuberância animal."; "Esta África é um continente absolutamente fabuloso, um país maravilhoso e jovem, e começo a admirar a estranha riqueza pânica dos negros. Se tivesse um gravador gravava por aqui algumas canções lindíssimas. Já sei uma ou duas de cor, letra e tudo."; "Isto é uma terra mágica e quente, tão bela que nos corta a respiração, onde tudo é excessivo e extraordinário." - é tão forte quanto sua repulsa - "Meu Deus, África - jê deteste ça... Há seis meses - faço seis meses depois de amanhã - que só vejo mata e chana, capim, arbustos, abatizes, soldados e tédio."; "Não sei, não sei. Sei só que tenho vivido os piores dias da minha vida nesta terra maldita." (ANTUNES, 2007, p. 55, 111, 113, 225, 333).
} 
A deslocação espacial e o seu corolário, a separação emocional da família e do país, levaram os narradores de CJ [Os cus de Judas] e CI [Conhecimento do inferno] a reavaliar as suas emoções e a olhar de uma nova forma os espaços nacionais costumeiros. [...].

Também os narradores de $\mathbf{C J}$ e $\mathbf{C I}$ se sentem fascinados pelas paisagens tranquilas angolanas, pelas cores de África, pelo silêncio da noite Africana, do silêncio carregado de ruído que África tem quando se cala (CJ). (VIEIRA, 2008, p. 201-202).

A partir do deslocamento espacial-afetivo, a escrita passa a ser impulsionada pela conscientização acerca do unheimlich $^{6}$ freudiano, na medida em que essa estranheza nos habita a todos e, mais que isso, constitui-nos como sujeitos cognoscentes: Kristeva chama a atenção para esse fato quando comenta que Freud, em seu "L'inquietante étrangeté", não fala em "estrangeiros", mas nos chama a "detectar a estranheza que há em nós" (KRISTEVA, 1994, p. 201). Quanto a esse aspecto, é reveladora a passagem de Os cus de Judas em que o escritor-narrador confessa à sua interlocutora "muda" um episódio de "estranheza": certa noite, telefonam-lhe e perguntam se fala de um número tal, completamente diferente do seu número de telefone. Em lugar de desfazer o engano e simplesmente desligar, o médico põe-se a tremer e a suar de aflição, sentindo-se um impostor, "um estranho numa casa estranha" (ANTUNES, 2003, p. 143). Um desterritorializado em território alheio.

Esse estranhamento algo familiar que o escritor-narrador apresenta em relação a si, aos espaços e às diversas esferas de sua vida sinaliza um mal-estar, uma indisposição, uma perturbação mal definida e indefinível em relação à própria existência. Nessa escrita, a negatividade da guerra, por exemplo, corporificada na mais incontornável ausência de sentido, não é dirimida nem mesmo pelo sujeito que a vivenciou em todas as suas manifestações: se o outro que jamais pisou em solo africano não pode deter nenhum saber sobre a negatividade que emana do espaço angolano, também não o pode o médico-escritor que, durante vinte e sete meses, submergiu completamente nesse espaço caótico:

[...] que sei eu que durante vinte e sete meses morei na angústia do arame farpado por conta das multinacionais, vi a minha mulher a quase morrer do

\footnotetext{
${ }^{6}$ Como foi já discutido por Freud em sua formulação do conceito de estranho, sabemos que, etimologicamente, a palavra unheimlich [estranho] comporta, em si mesma, a palavra familiar [heimlich], sugerindo que aquilo que há de mais estranho em nós é, precisamente, o que nos é mais próprio, mas que foi, de alguma forma, "encoberto", permanecendo submerso.
} 


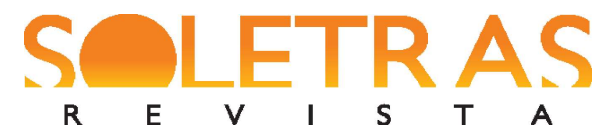

N. $38-2019.2$ - DENIS LEANDRO FRANCISCO

falciparum, assisti ao vagaroso fluir do Dondo, fiz uma filha na Malanje dos diamantes, contornei os morros nus de Dala-Samba povoados no topo pelos tufos de palmeiras dos túmulos dos reis Jingas, parti e regressei com a casca de um uniforme imposta no corpo, que sei eu de África? (ANTUNES, 2003, p. 44).

Memória de elefante, Os cus de Judas e Conhecimento do inferno constroem-se, assim, como antiépicos: o soldado - o herói - que volta da guerra e passa a narrar seus feitos gloriosos é apropriado pela prosa do escritor-em-formação Lobo Antunes para ser solapado, negativado e desterritorializado. O médico-narrador desses três romances - e o próprio escritor - é, assim, uma espécie de antiUlisses, perdeu o aspecto solar que a épica lhe conferia e se move, agora, no espaço desterritorializado que cabe ao herói lunar. Esse anti-herói empreende, ao longo das três narrativas, sua catábase particular, sua "descida aos infernos" que, como consequência, possibilitará a emergência da escrita literária:

- Deolinda, informou-a ele, estou a tocar no fundo.

Ela abanou o rosto em bico de tartaruga bondosa:

- Nunca mais tem fim essa descida?

O médico ergueu os botões de punho ao tecto de caliça descamada numa patética imploração bíblica, na esperança de que a teatralidade voluntária ocultasse parte do seu sofrimento verdadeiro:

- Você encontra-se (observe-me bem) por felicidade sua e infelicidade minha defronte do maior espeleólogo da depressão: oito mil metros de profundidade oceânica da tristeza, negrume de águas gelatinosas sem vida salvo um ou outro repugnante monstro sublunar de antenas, e tudo isto sem batiscafo, sem escafandro, sem oxigénio, o que significa, obviamente, que agonizo (ANTUNES, 2003, p. 29-30).

A “descida aos infernos" parece interminável e a narrativa se desenvolve como uma espécie de contínuo agonizar do escritor-narrador, que não emerge desse seu leito-fosso em nenhum momento, ao contrário, arrasta consigo no percurso da queda toda a sua "memória de elefante", com a qual reterritorializa, em sua escritura, sua vivência da guerra e do espaço angolano.

Esse escritor-em-formação egresso da guerra colonial não reterritorializa esse espaço a partir de uma memória de grandes feitos a serem narrados e transmitidos como “aprendizagem", não há nada a transmitir: nenhum ensinamento, nenhuma verdade, nenhum 
saber proveniente desses vinte e sete meses de desterro. Como os soldados que Walter Benjamin evoca em seu clássico ensaio "Experiência e pobreza" (BENJAMIN, 1994a, p. 115), soldados que retornavam silenciosos dos campos de batalha da Primeira Guerra, "mais pobres em experiências comunicáveis, e não mais ricos", esse escritor-em-formação reterritorializa esses espaços não por meio de agenciamentos como a sabedoria de um conselho a ser transmitido às gerações mais jovens, mas agenciando formas esvaziadas e esvaziadoras de negatividade: esse escritor-narrador comunica, a quem interessar possa, a sua desorientação [Ratlosigkeit] pessoal, comunica, portanto, a perda da experiência [Erfahrung] (GAGNEBIN, 1994, p. 73), ao mesmo tempo em que inscreve, na árdua escritura dos seus três romances de estreia, a ascensão da forma negativada da experiência: a vivência [Erlebnis] no/do vazio. O conselho [Rat] (BENJAMIN, 1994b, p. 197-221) benjaminiano esvazia-se e adquire um sinal "negativo", atuando nessas narrativas de formação como um "anticonselho" desse escritor-psiquiatra-narrador:

Pela minha parte, sabe como é, não peço tanto a vida: as minhas filhas crescem numa casa de que cada vez menos me recordo, de móveis bebidos pelas águas de sombra do passado, as mulheres que encontrei depois abandonei-as ou abandonaram-me numa tranquila decepção mútua em que não houve sequer lugar para esse tipo de ressentimento que é como que o sinal retrospectivo de uma espécie de amor, e envelheço sem graça num andar demasiado grande para mim, observando à noite, da secretária vazia, as palpitações do rio, através da varanda fechada cujo vidro me devolve o reflexo de um homem imóvel, de queixo nas mãos, em que me recuso a reconhecer-me, e que teima em fitar-me numa obstinação resignada. Talvez que a guerra tenha ajudado a fazer de mim o que sou hoje e que intimamente recuso: um solteirão melancólico a quem se não telefona e cujo telefonema ninguém espera, tossindo de tempos a tempos para se imaginar acompanhado, e que a mulher a dias acabará por encontrar sentado na cadeira de baloiço em camisola interior, de boca aberta, roçando os dedos roxos no pêlo cor-de-novembro da alcatifa (ANTUNES, 2003, p. 68-69).

$\mathrm{O}$ conselho que o escritor-psiquiatra-narrador oferece às demais personagens e ao leitor é, precisamente, o da impossibilidade de dar conselhos, da impossibilidade da partilha, da impossibilidade, enfim, da própria experiência em sua vertente afirmativa. No espaço angolano, comenta o narrador, a negatividade da guerra parece tê-lo convertido no que ele é hoje: um sujeito esvaziado, para o qual não há lugar nem mesmo para os sentimentos 


\section{SOLETRAS}

N. 38 - 2019.2 - DENIS LEANDRO FRANCISCO

negativos, há apenas a mais absoluta resignação quanto ao apagamento de todas as coisas, resignação que, claro esteja, opera apenas no nível do enunciado: no plano da enunciação, a "energia de um dizer compulsivo" detectada na prosa antuniana denota uma empreitada quase obsessiva na tentativa de dizer todas as coisas por meio da escrita.

Isso que se constituiria, portanto, como a impossibilidade radical da escrita - já que também a escrita se constitui como uma modalidade de transmissão da experiência -, tornase, nessas narrativas de formação, condição sine qua non para escrever: narra-se a partir do esvaziamento da experiência, a partir da própria condição de negatividade, percebida em toda a sua radicalidade no espaço angolano da guerra colonial. A "Arte da Catalogação da Angústia" (ANTUNES, 2006b, p. 10.), a "dolorosa aprendizagem da agonia" (ANTUNES, 2003, p. 9) e o "conhecimento do inferno" (ANTUNES, 2006a, p. 22) são, também, a catalogação, a aprendizagem e o conhecimento da escrita.

A esse propósito, é importante tecer a seguinte consideração: Em D’este viver aqui neste papel descripto: cartas da guerra, na carta datada de 1-7-71, Lobo Antunes apercebe-se do estrangulamento da sua própria voz: "Surpreende-me o meu próprio silêncio, e a minha voz. Falo pouco, e tudo o que digo é num tom seco e melancólico, que não era o meu.”. Ora, é também do declínio da transmissão oral da experiência que Benjamin trata em seu citado ensaio de 1933, já que é às narrativas orais das sociedades artesanais que ele se reporta, não se referindo, portanto, a nenhuma modalidade escrita de transmissão da experiência. Porém, a esse declínio da voz indiciado nas cartas antunianas poder-se-ia, talvez, correlacionar uma notável ascensão do código verbal escrito: um pouco mais adiante, o narrador dessas cartas se autoindaga se sua "pobreza de experiência" na guerra colonial poderia interessar a quem quer que fosse e, mais ainda, se há algo nessa experiência que se possa contar:

Penso escrever amanhã ao Pedro, pois recebi uma carta dele, a que não respondi, há cerca de 12.000 anos. Mas que posso eu dizer às pessoas? Que tenho para contar? Que faz um tempo húmido de nevoeiro e frio, que não chove, que esta estadia me rói por dentro o caroço da alma? [...]. A chateza da minha vida impregna tudo (ANTUNES, 2007, p. 212, 223, grifos nossos).

Com a publicação dos seus três romances de formação, pode-se, então, pensar que essa incapacidade de expressão oral, já diagnosticada nas cartas da guerra, tenha se 


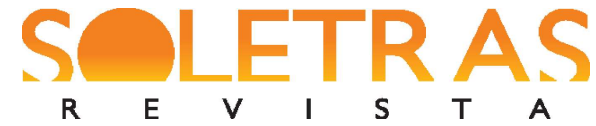

N. $38-2019.2$ - DENIS LEANDRO FRANCISCO

reterritorializado na inflada e alucinante "escrita compulsiva" do escritor Lobo Antunes, que, justamente, num paroxismo próprio dos seus textos literários, escreve a impossibilidade de uma experiência efetiva, entendida como compartilhamento, comunhão, transmissibilidade. Quem fala (e escreve) nas narrativas antunianas, desde o início de sua produção ficcional, é já um eu-ele desterritorializado porque dispersado pela força da negatividade da guerra em Angola e, assim, sua enunciação se fará também sobre esse espaço desterritorializado, a escrita constituindo-se nessa superfície lisa onde se cruzam espacialidades distintas, cortadas por temporalidades também múltiplas e distintas.

Ora, nesse espaço discursivo-literário, as subjetividades não poderiam ser senão subjetividades múltiplas que se desterritorializam indefinidamente para se reterritorializarem em uma outra coisa que, por sua vez, se reterritorializará em uma outra, e outra, sem possibilidade de, ou aspiração a, uma articulação mais precisa e estável. A criança de Benfica se reterritorializa no alferes miliciano e no tenente da guerra colonial de Angola; este, por sua vez, se reterritorializa no psiquiatra lisboeta de família tradicional, pai e em processo de separação; todos esses sujeitos se desterritorializarão, cada um a sua vez, para se reterritorializarem no escritor António Lobo Antunes:

[...] no Verão anterior, passara três meses com a Isabel para acabar a Memória de Elefante, que arrastava atrás de si havia meses num desprazer de maçada, construindo capítulo a capítulo na lentidão penosa do costume, à espera da chegada das palavras como um mártir de Revelações improváveis. (ANTUNES, 2006a, p. 48).

\section{Considerações finais}

Este artigo procurou mostrar aspectos da formação do escritor António Lobo Antunes perspectivando algumas relações entre espaço e escrita nos seus três romances de estreia. Esses romances, ainda que se estruturem sobre três grandes eixos fundamentais, têm no processo de trânsito do médico-psiquiatra pelo espaço da guerra colonial portuguesa em Angola a desterritorialização necessária ao engendramento da escrita desse escritor-emformação: 
É certo que a sua deriva existencial não é exclusivamente imputável à guerra colonial, mas não é menos verdade que a guerra deixou nele marcas indeléveis, que assumem as proporções de um trauma que foi decisivo para a sua crise interior. E mesmo as reminiscências positivas de África acabam por se revelar nefastas, na medida em que o protagonista as recorda como uma realidade que perdeu em definitivo e fundamenta os laivos de alienação que lhe perturbam a identidade no seu regresso despaisado a Portugal. (SOUSA, 2008, p. 205).

Desterritorializar, escrever, reterritorializar. Simultaneamente à desterritorialização do espaço africano pela negatividade da guerra colonial processa-se a desterritorialização do médico-psiquiatra e sua reterritorialização em escritor. Não se trata apenas, aqui, de uma relação temática de ordem topográfica proposta pelo texto literário como mimese, mas do estabelecimento de uma continuidade entre o espaço atravessado e o espaço narrado, um continuum entre exterior e interior. Evidência do estabelecimento dessa relação recíproca é que, formado o escritor, a territorialidade do espaço angolano expandir-se-á decisivamente por toda a sua obra, "reflectindo uma ligação afetiva que o tempo não logrou destruir" (VIEIRA, 2008, p. 204).

\section{Referências}

ABREU, Graça. África. In: SEIXO, Maria Alzira et al. Dicionário da obra de António Lobo Antunes, vol. 1. Lisboa: Imprensa nacional/Casa da moeda, 2008. p. 187-189.

ANTUNES, António Lobo. Conhecimento do inferno. Rio de Janeiro: Objetiva, 2006a.

ANTUNES, António Lobo. Memória de elefante. Rio de Janeiro: Objetiva, 2006b.

ANTUNES, António Lobo. Os cus de Judas. Rio de Janeiro: Objetiva, 2003.

ANTUNES, António Lobo. D'este viver aqui neste papel descripto: cartas da guerra. Lisboa: Dom Quixote, 2007.

ARNAUT, Ana Paula. Entrevistas com António Lobo Antunes, 1979-2007: confissões do trapeiro. Coimbra: Almedina, 2008.

BARTHES, Roland. A morte do autor. In: BARTHES, Roland. O rumor da língua. Trad. Mário Laranjeira. São Paulo: Editora Brasiliense, 1988. 


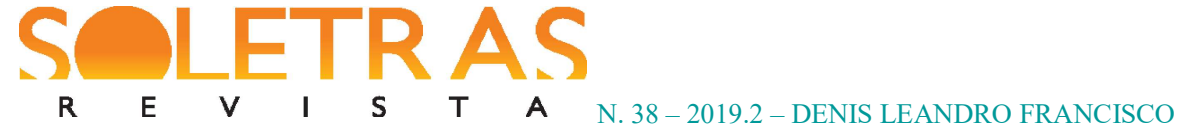

BENJAMIN, Walter. Experiência e pobreza. In: BENJAMIN, Walter. Magia e técnica, arte e política: ensaios sobre literatura e história da cultura. 7. ed. Trad. Sergio Paulo Rouanet. São Paulo: Brasiliense, 1994a. Obras escolhidas, v.1. p.114-119. [1933].

BENJAMIN, Walter. O narrador: considerações sobre a obra de Nikolai Leskov. In: BENJAMIN, Walter. Magia e técnica, arte e política: ensaios sobre literatura e história da cultura. 7. ed. Trad. Sergio Paulo Rouanet. São Paulo: Brasiliense, 1994b. Obras escolhidas, v.1. p. 197-221. [1936].

DELEUZE, G; GUATTARI, F. s/d. O Anti-Édipo: capitalismo e esquizofrenia. Lisboa: Assírio \& Alvim. [ed. original: 1972]

DELEUZE, Gilles; GUATTARI, Félix. 1440: o liso e o estriado. In: DELEUZE, Gilles; GUATTARI, Félix. Mil platôs: capitalismo e esquizofrenia, vol. 5. Trad. Peter Pál Pelbart e Janice Caiafa. São Paulo: Ed. 34, 1997a. p. 179-214. (Coleção TRANS). [1980].

DELEUZE, Gilles; GUATTARI, Félix. Conclusão: regras concretas e máquinas abstratas. In: DELEUZE, Gilles; GUATTARI, Félix. Mil platôs: capitalismo e esquizofrenia, vol. 5. Trad. Peter Pál Pelbart e Janice Caiafa. São Paulo: Ed. 34, 1997b. p. 215-232. (Coleção TRANS). [1980].

DELEUZE, Gilles; GUATTARI, Félix. Introdução: rizoma. In: DELEUZE, Gilles; GUATTARI, Félix. Mil platôs: capitalismo e esquizofrenia, vol. 1. Trad. Aurélio Guerra Neto e Celia Pinto Costa. São Paulo: Ed. 34, 1995b. p. 11-37. (Coleção TRANS). [1980].

GAGNEBIN, Jeanne Marie. Não contar mais? In: GAGNEBIN, Jeanne Marie. História e narração em Walter Benjamin. São Paulo: Perspectiva, 1994c. p. 63-82. (Coleção Estudos. Filosofia).

GUATTARI, Félix.; ROLNIK, Suely. Micropolítica: cartografias do desejo. 4. ed. Petrópolis: Vozes, 1996. [1986].

KRISTEVA, Julia. Estrangeiros para nós mesmos. Trad. Maria Carlota Carvalho Gomes. Rio de Janeiro: Rocco, 1994.

MARGOLIS, Joseph Zalman. Negativities: the limits of life. Columbus: Charles Merrill, 1975.

SEIXO, Maria Alzira et al. Dicionário da obra de António Lobo Antunes, vol. 1. Lisboa: Imprensa nacional/Casa da moeda, 2008.

SOUSA, Sérgio Paulo Guimarães de. Angola (Em ME). In: SEIXO, Maria Alzira et al. Dicionário da obra de António Lobo Antunes, vol. 1. Lisboa: Imprensa nacional/Casa da moeda, 2008. p. 204-205.

VIEIRA, Agripina Carriço. Angola. In: SEIXO, Maria Alzira et al. Dicionário da obra de António Lobo Antunes, vol. 1. Lisboa: Imprensa nacional/Casa da moeda, 2008. p. 200-204. 


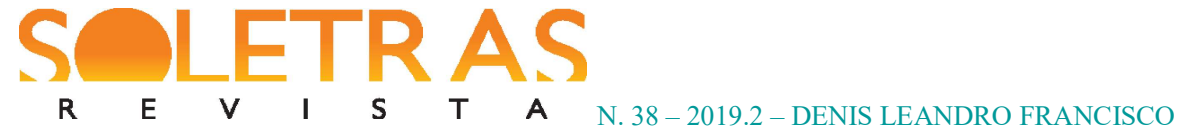

\title{
An agonizing learning: space of/and writing in António Lobo Antunes
}

\begin{abstract}
This article relates space and writing in the first three novels of the Portuguese writer António Lobo Antunes: Elephant Memory (1979), South of nowhere (1979) and Knowledge of hell (1980). The aim is to examine the transit of the then-physician-psychiatrist Lobo Antunes through the African space during the colonial war in Angola as what makes possible the writing of the literary text. His writing emerges due to the writer-in-formation's awareness of what Joseph Margolis (1975) philosophically defined as human negativities - basic forms of loss and limitation of life and meaning -, process that Walter Benjamin $(1933,1936)$ related to the "destruction of experience". The analysis undertaken is based on the theoretical notion of territory, deterritorialization and reterritorialization (DELEUZE; GUATTARI, 1980, GUATTARI; ROLNIK, 1986) and it indicates that simultaneously to the relative deterritorialization of Angolan space by the negativity of the colonial war, the absolute deterritorialization of the physician-psychiatrist and his reterritorialization as a writer take place.
\end{abstract}

Keywords: António Lobo Antunes. Space. Negativity. Re-deterritorialization. Writing

Recebido em: 14 de junho de 2019.

Aceito em: 04 de setembro de 2019. 